\title{
Ursocholic acid: bile acid and bile lipid dose response and clinical studies in patients with gall stones
}

\author{
P J HOWARD, D GLEESON, G M MURPHY, AND R H DOWLING \\ From the Gastroenterology Unit, Guy's Campus, Division of Medicine, United Medical and Dentals Schools of \\ Guy's and St Thomas's Hospitals, London
}

SUMMARY The biliary bile acid and bile lipid responses to six weeks treatment with approximately 5,10 , and $15 \mathrm{mg} / \mathrm{kg} /$ day of ursocholic acid (UCA) were studied in 11 gall stone patients. Maximum enrichment of bile with UCA (24 (SE) $4.9 \%$ ) occurred with $15 \mathrm{mg} \mathrm{UCA} / \mathrm{kg} /$ day. The maximum reduction in biliary cholesterol saturation was seen with the $10 \mathrm{mg} / \mathrm{kg} /$ day dose when the moles $\%$ cholesterol fell from $14(2.4) \%$ before treatment to $5.6(0.83) \%(p<0.02)$ and the saturation index fell from $1.4(0.23)$ to $0.77(0 \cdot 13)(p<0 \cdot 05)$. Clinical studies of the safety and efficacy of UCA in dissolving gall stones were carried out in 13 patients treated for up to two years with a dose of approximately $10 \mathrm{mg} / \mathrm{kg} /$ day. Diarrhoea caused withdrawal of treatment in three patients. There were no significant changes in liver function or haematology tests but fasting serum cholesterol tended to rise during treatment. Of nine patients treated for $>6$ months, only one showed complete gall stone dissolution. As UCA may cause diarrhoea and hypercholesterolaemia, has only a modest effect on biliary cholesterol saturation and low gall stone dissolution efficacy, it is unlikely to replace existing forms of gall stone dissolution therapy.

Both chenodeoxycholic (CDCA) and ursodeoxycholic acid (UDCA) are established gall stone dissolving agents. ${ }^{12}$ Chenodeoxycholic acid, however, causes dose related diarrhoea ${ }^{34}$ and hypertransaminasaemia. ${ }^{40}$ Although UDCA does not have these disadvantages, we have found that it is less effective than CDCA in dissolving gall stones completely, ${ }^{7}$ partly because of acquired gall stone calcification..$^{7-9}$ The efficacy of a combination of CDCA and UDCA is variable ${ }^{10-13}$ and the ideal bile acid therapy for gall stones has still to be found.

Ursocholic acid (UCA) is the 7 beta epimer of the naturally occurring primary bile acid, cholic acid (Fig. 1). Cholic acid (CA) administration does not reduce biliary cholesterol saturation, unless its 7 alpha dehydroxylation to deoxycholic acid (DCA) is prevented by concomitant antibiotic treatment. ${ }^{14}$ Because 7 beta dehydroxylation is less efficient than 7

Address for correspondence: Professor R Hermon Dowling, Gastroenterology Unit, 18th floor, Guy's Tower, Guy's Hospital, London SE1 9RT.

Received for publication 30 June 1988. alpha dehydroxylation, ${ }^{15}$ we reasoned that UCA might not be degraded to DCA, might not cause diarrhoea and might, therefore, be an effective gall stone dissolving agent. Information about UCA treatment in man is limited. Loria $e a l^{16}$ studied the effects of acute (five hour) intraduodenal infusions of $1 \mathrm{~g} \mathrm{UCA} / \mathrm{h}$ on T-tube bile in three postcholecystectomy patients. This enriched the bile with UCA conjugates to a plateau of $90 \%$. They also examined the effects of two weeks oral treatment with either 10 or $15 \mathrm{mg} \mathrm{UCA} / \mathrm{kg} /$ day, on the bile acid and bile lipid composition of fasting, bile rich duodenal fluid. Arguably, however, two weeks is too short a time to establish a new steady state in bile composition. ${ }^{17}$ Zuin and Podda ${ }^{18}$ treated six patients with UCA, all of whom had stones which were ideally suited for dissolution therapy and found complete gall stone dissolution in three.

The aims of the present study were two-fold: first, to establish the dose response of biliary bile acid and bile lipid composition to treatment with UCA and second, to examine the gall stone dissolution efficacy, side effects and safety of longterm UCA treatment. 
Cholic acid

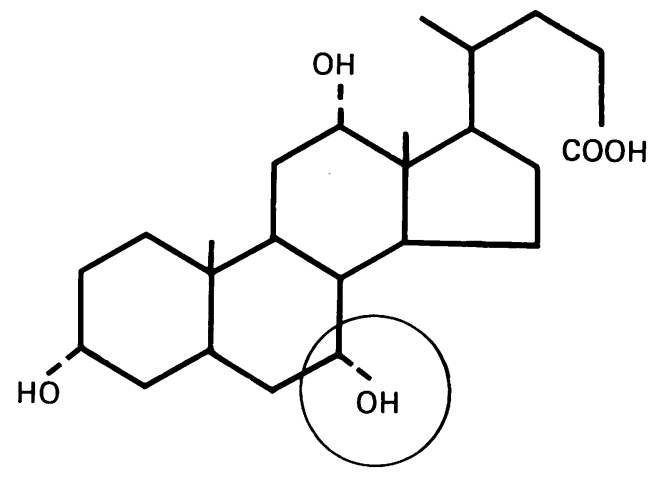

$3 \alpha, 7 \alpha, 12 \alpha$, Trihydroxycholanoic acid
Ursocholic acid

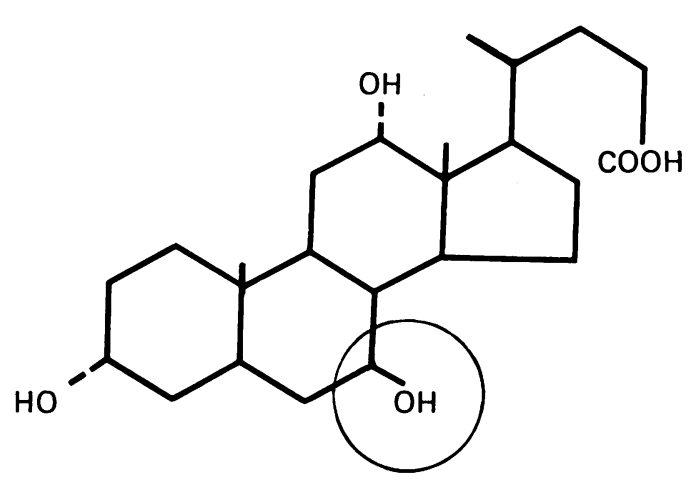

$3 \alpha, 7 \beta, 12 \alpha$, Trihydroxycholanoic acid

Fig. 1 Structure of ursocholic acid (UCA) contrasted with its parent bile acid, cholic acid (CA). As indicated by the ringed groups, the only difference is in the configuration of the 7 hydroxyl group - beta for UCA and alpha for CA.

\section{Methods}

PATIENTS

Eleven patients took part in the dose response study (patients 1-11, Table 1). One patient (number 2) had small, asymptomatic recurrent gall stones, after dissolution with UDCA. Four patients presented with non-specific dyspepsia. The remaining six had a clinical history and/or biochemical evidence of biliary colic.

Before the study, all patients underwent ultrasonography and cholecystography, all had radiolucent gall stones and all but two had stones measuring $<20 \mathrm{~mm}$ (maximum diameter) in 'functioning' gall bladders (patent cystic ducts).

Table 1 Clinical details of the 13 patients who took part in the dose response and efficacy studies with ursocholic acid

\begin{tabular}{llllrrr}
\hline $\begin{array}{l}\text { Patient } \\
\text { no }\end{array}$ & Sex & Age & $\begin{array}{l}\text { Weight } \\
(\mathrm{kg})\end{array}$ & $\%$ IBW & $\begin{array}{l}\text { Stones } \\
(\mathrm{n})\end{array}$ & $\begin{array}{l}\text { Stones max } \\
\text { diameter } \\
(\mathrm{mm})\end{array}$ \\
\hline 1 & M & 46 & 84 & 99 & 3 & 13 \\
2 & M & 67 & 83 & 118 & 3 & 5 \\
3 & M & 66 & 92 & 114 & $>10$ & 5 \\
4 & M & 45 & 81 & 100 & 2 & $<5$ \\
5 & F & 52 & 87 & 141 & 1 & 28 \\
6 & M & 59 & 83 & 101 & 6 & 10 \\
7 & F & 57 & 74 & 117 & 2 & 20 \\
8 & F & 75 & 61 & 104 & 2 & 11 \\
9 & F & 56 & 78 & 123 & 2 & 17 \\
10 & F & 27 & 75 & 131 & $>15$ & 18 \\
11 & M & 55 & 71 & 87 & 1 & 14 \\
12 & F & 57 & 65 & 98 & 3 & 5 \\
13 & F & 61 & 73 & 116 & $>20$ & $<5$ \\
\hline
\end{tabular}

In addition to the patients entered into the dose response study, two further patients were treated with UCA in a dose of approximately $10 \mathrm{mg} / \mathrm{kg} / \mathrm{day}$ for up to 24 months to assess its gall stone dissolution efficacy.

\section{BILIARY BILE ACIDS AND BILE LIPIDS}

For the dose response studies, fasting bile rich fluid was aspirated from the duodenum after an intravenous injection of 100 Ivy Dog Units of cholecystokinin (Pancreozymin, Boots PLC, Nottingham, UK). In the first seven patients, the bile rich fluid was obtained before treatment and again after six week courses each of 5,10 , and $15 \mathrm{mg} \mathrm{UCA} / \mathrm{kg} /$ day. In the remaining four, duodenal bile was studied before and after six weeks treatment with $15 \mathrm{mg} / \mathrm{kg} /$ day of UCA. The bile samples were stored at $-20^{\circ} \mathrm{C}$ until analysed for their bile acid, phospholipid and cholesterol content, as previously described. ${ }^{19}$ Individual bile acids were analysed by gas liquid chromatography.

The biliary cholesterol saturation indices (SIs) were calculated using the Thomas and Hofmann polynominal equation ${ }^{20}$ and the solubility limits of Hegardt and Dam $^{21}$ and Holzbach et al..$^{22}$ No correction was made for changes in biliary bile acid composition. ${ }^{23}$

\section{SERUM LIPIDS AND LIVER FUNCTION TESTS}

Blood samples were taken for full blood counts, serum bilirubin, alanine transaminase, alkaline phosphatase, gamma glutamyl transpeptidase, total protein and albumin concentrations and fasting lipids before treatment, at the time of each intubation, and every six months thereafter. Lipoprotein electro- 


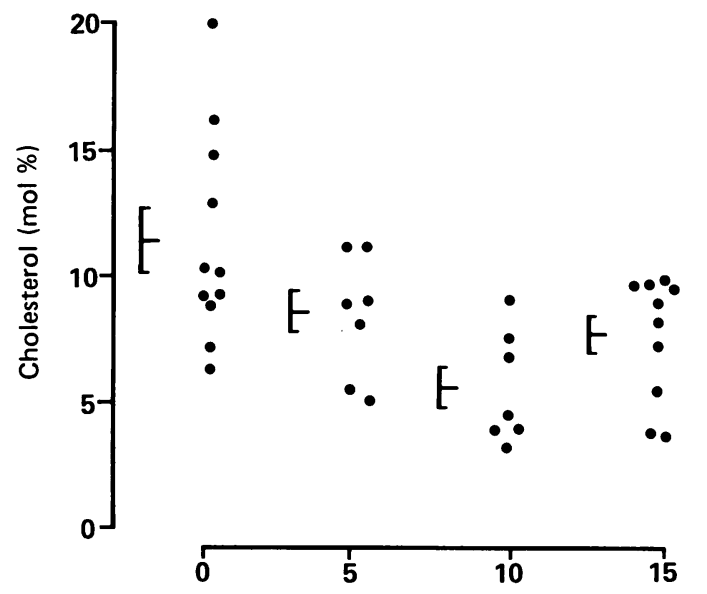

Table 2 Biliary bile acid composition (duodenal bile) in gall stone patients studied before (baseline) and during six weeks treatment with approximately 5,10 , and $15 \mathrm{mg} \mathrm{UCA/}$ $\mathrm{kg} /$ day

\begin{tabular}{|c|c|c|c|c|c|c|}
\hline & $\begin{array}{c}L C A \\
\%\end{array}$ & $\underset{\%}{D C A}$ & $\underset{\%}{C D C A}$ & $\underset{\%}{U D C A}$ & $\begin{array}{r}C A \\
\%\end{array}$ & $\begin{array}{c}7 K L C A \\
\%\end{array}$ \\
\hline \multicolumn{7}{|l|}{ Baseline } \\
\hline $\begin{array}{l}\text { Number } 1 \\
\text { Mean }\end{array}$ & 11 & $\begin{array}{l}11 \\
20 \cdot 4\end{array}$ & $\begin{array}{l}11 \\
28.0\end{array}$ & $\begin{array}{l}11 \\
2 \cdot 0\end{array}$ & $\begin{array}{l}11 \\
43 \cdot 4\end{array}$ & 11 \\
\hline SE & $1 \cdot 3$ & $2 \cdot 4$ & $3 \cdot 4$ & 1.8 & 3.4 & $0 \cdot 5$ \\
\hline \multicolumn{7}{|c|}{$5 \mathrm{mg} / \mathrm{kg} /$ day } \\
\hline Number & 7 & 7 & 7 & 7 & 7 & 7 \\
\hline Mean & $4 \cdot 2$ & $28 \cdot 8$ & $21 \cdot 6$ & 1.4 & 29.9 & 0.00 \\
\hline SE & 0.7 & $4 \cdot 8$ & $4 \cdot 9$ & $1 \cdot 4$ & $2 \cdot 3$ & 0.00 \\
\hline \multicolumn{7}{|c|}{$10 \mathrm{mg} / \mathrm{kg} /$ day } \\
\hline Number & 7 & 7 & 7 & 7 & 7 & 7 \\
\hline Mean & $5 \cdot 5$ & $27 \cdot 2$ & 19.9 & $1 \cdot 1$ & $23 \cdot 0$ & 0.00 \\
\hline SE & $1 \cdot 3$ & $5 \cdot 4$ & $4 \cdot 6$ & $1 \cdot 1$ & $5 \cdot 4$ & 0.00 \\
\hline \multicolumn{7}{|c|}{$15 \mathrm{mg} / \mathrm{kg} /$ day } \\
\hline Number 1 & & 10 & 10 & 10 & 10 & 10 \\
\hline Mean & $4 \cdot 0$ & 29.0 & $17 \cdot 4$ & $3 \cdot 1$ & 19.9 & 1.6 \\
\hline SE & $1 \cdot 3$ & $3 \cdot 6$ & $2 \cdot 0$ & $2 \cdot 1$ & 4.9 & 1.2 \\
\hline
\end{tabular}

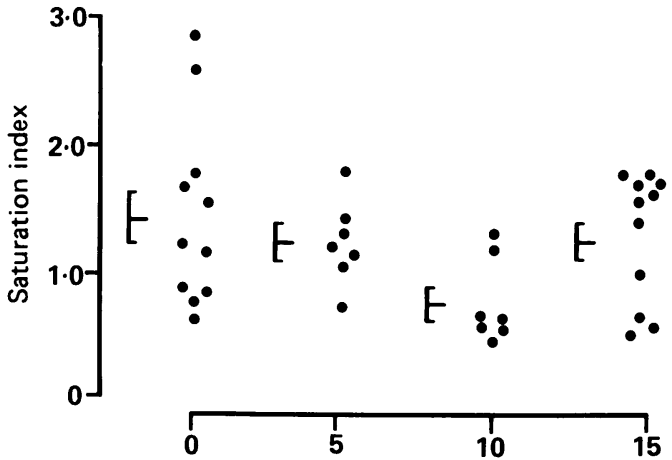

Approximate daily dose of UCA $(\mathrm{mg} / \mathrm{kg} / \mathrm{day})$

Fig. 2 Moles \% cholesterol (upper panel) and the cholesterol saturation index, as defined by Hegardt and Dam ${ }^{21}$ and Holzbach et $\mathrm{al}^{22}$ (lower panel), in fasting bile rich duodenal fluid obtained before treatment $(0 \mathrm{mg} \mathrm{UCA/ \textrm {kg } /}$ day) and after six weeks treatment with approximately 5, 10, and $15 \mathrm{mg} U C A / \mathrm{kg} /$ day. The saturation index values are uncorrected for non-micellar solubilisation of cholesterol (individual data points with means (SE)).

phoresis was done only if abnormalities of serum total lipid concentrations were found.

STATISTICAL ANALYSIS

Results were expressed as means (SE). Statistical analysis was by Student's paired or unpaired $t$ tests or analysis of variance, as appropriate.

\section{Results}

BILE ACIDS AND BILE LIPIDS: DOSE RESPONSE STUDIES

The effect of UCA treatment on the moles \% cholesterol in bile and on the associated SIs, is illustrated in Figure 2. The corresponding changes in biliary bile acid composition are given in Table 2 . The data for the per cent UCA conjugates in bile with the different UCA doses, are shown in Figure 3.

BILE LIPIDS

Before treatment, the moles \% bile acids, phospholipids and cholesterol were 64.4 (SE 1.95), 23.3 $(1.7) \%$, and $11.4(1.27) \%$ respectively, giving a mean calculated SI of $1.44(0.22)$.

After six weeks treatment with approximately $5 \mathrm{mg}$ and $10 \mathrm{mg} \mathrm{UCA} / \mathrm{kg} /$ day, the moles \% cholesterol fell significantly to $8.5(0.94) \%(\mathrm{p}<0.05$, compared with baseline $)$, and to $5.6(0.83) \%(\mathrm{p}<0.02)$ respectively, then rose slightly to $7 \cdot 7(0 \cdot 76)$ on the $15 \mathrm{mg} / \mathrm{kg}$ dose. The corresponding SIs were $1.25(0.14), 0.77(0.13)$ $(\mathrm{p}<0 \cdot 05)$, and $1.26(0 \cdot 16)$, respectively.

Therefore, SIs were significantly lower than baseline values only with $10 \mathrm{mg} / \mathrm{kg}$ dose and even then, two patients (numbers 2 and 6 ) had supersaturated bile (SIs of 1.3 and 1.2 respectively).

BILIARY BILE ACIDS

The molar percentage of UCA conjugates in bile rose from undetectable levels before treatment to 14 (3.6)\% with $5 \mathrm{mg}(\mathrm{p}<0.001), 23(3.6) \%$ with the 10 $\mathrm{mg}(\mathrm{p}<0.001)$ and $24(5 \cdot 1) \%$ with the $15 \mathrm{mg} \mathrm{UCA} / \mathrm{kg} /$ day $(\mathrm{p}<0.001)$ doses (Fig. 3).

The enrichment of bile with UCA was 'accommodated' by reciprocal falls in the per cent of both the primary bile acids $\mathrm{CA}$ and CDCA. The reduction in the proportion of CA, however, was greater than that of CDCA with the result that the molar ratio of 


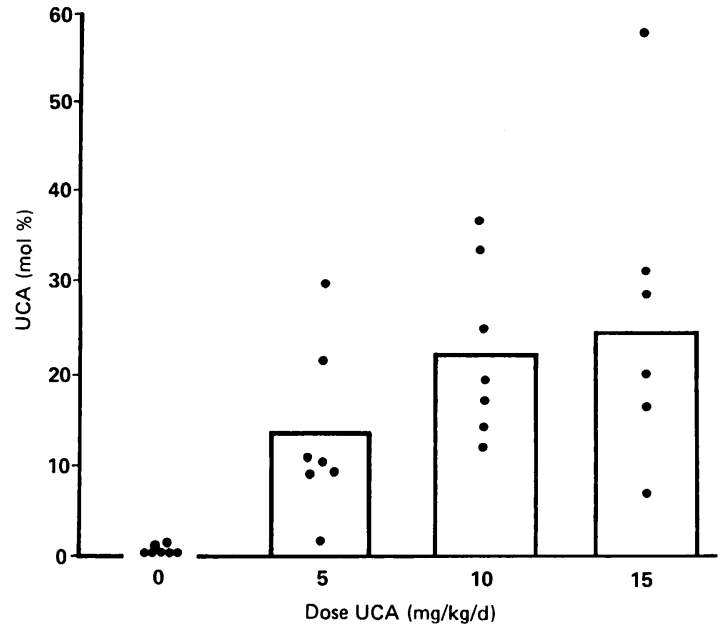

Fig. 3 Effect of UCA treatment on the molar percentage of $U C A$ conjugates in bile-rich duodenal fluid (means (SE)).

CA:CDCA which was $1 \cdot 50: 1$ before treatment, fell to $1 \cdot 38: 1$ with the $5 \mathrm{mg}, 1 \cdot 15: 1$ with the $10 \mathrm{mg}$ and $1 \cdot 14: 1$ with the $15 \mathrm{mg} \mathrm{UCA} / \mathrm{kg} /$ day doses, respectively.

Whilst the molar percentage of CA (normally the main precursor of DCA) fell, there was a $41 \%$ increase in the mean per cent DCA conjugates between the pretreatment and the $5 \mathrm{mg} / \mathrm{kg}$ UCA treatment periods, but with little overall change thereafter (Table 2). This implies that during UCA therapy, either there was a major increase in bacterial 7 alpha dehydroxylation of the substrate $\mathrm{CA}$ or, more likely, in 7 beta dehydroxylation of the administered UCA and its conjugates. This suggestion is supported indirectly by the molar ratios of product: potential substrate. The DCA:CA ratio increased markedly from $0 \cdot 47: 1$ before treatment to $0 \cdot 96: 1$ with the $5 \mathrm{mg}$, $1 \cdot 17: 1$ with the $10 \mathrm{mg}$ and $1 \cdot 45: 1$ with the $15 \mathrm{mg} \mathrm{UCA}$ doses. If both CA and UCA had acted as substrates for DCA, however, one would have expected a more fixed DCA:(CA+UCA) ratio. This, essentially is what was found, the mean DCA:(CA+UCA) ratios being $0 \cdot 46: 1,0 \cdot 66: 1,0 \cdot 56: 1$, and $0 \cdot 66: 1$.

The fact that the molar percentage of the potentially hepatotoxic bile acid, lithocholic acid (LCA), was maintained during UCA therapy, despite falling proportions of its precursor CDCA, suggests that the dehydroxylation fraction must have increased although only to a modest extent (Table 2).

RELATIONSHIP BETWEEN MOLES \% CHOLESTEROL AND THE \% UCA CONJUGATES IN BILE

The relationship between the moles $\%$ cholesterol and the \% UCA conjugates in bile, is shown in Figure

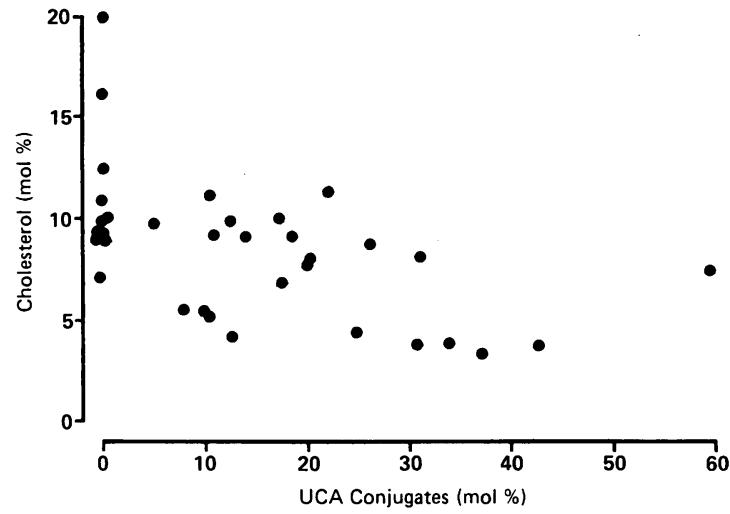

Fig. 4 Relationship between the moles \% cholesterol and the per cent UCA conjugates in fasting bile-rich duodenal fluid. From these data, a linear regression line $(n=35$; $y=25.67-1.22 \times ; r=0.468 ; p<0.005$ ) may be derived such that, on average, for every $10 \%$ increase in the moles $\%$ UCA conjugates, there is a $16 \%$ drop in the moles $\%$ cholesterol in bile (95\% confidence limits $9-22 \%)$.

4. There was a trend towards lower moles \% cholesterol values as the bile became enriched with UCA conjugates.

\section{GALL STONE DISSOLUTION EFFICACY}

Of the 13 patients who started UCA treatment, four stopped in less than six months before any ontreatment ultrasound or $x$-ray studies had been carried out. In three, this was because of intolerable diarrhoea whilst the fourth, who had been symptom free, simply defaulted from follow up.

Nine patients remained on treatment at six months, seven at 12 months, three at 18 months and one at 24 months. Of these nine patients, only one (patient 2) showed complete gall stone dissolution (confirmed by two consecutive cholecystograms and two ultrasonograms three months apart during continued treatment), after 18 months UCA therapy in a dose of $10.8 \mathrm{mg} / \mathrm{kg} / \mathrm{day}$. In the dose response study, his bile had been supersaturated with cholesterol (SI of 1.3 ) during treatment with $10 \mathrm{mg} / \mathrm{kg} /$ day. Four patients underwent elective cholescystectomy, of whom three had experienced episodes of mild biliary colic during treatment.

\section{ADVERSE SIDE EFFECTS}

Caused by gall stones

No patient experienced cholecystitis, cholangitis, obstructive jaundice, pancreatitis, or severe biliary colic whilst on treatment.

\section{Caused by UCA therapy}

The only adverse symptom during UCA therapy was 
Table 3 Results of liver function tests and fasting serum lipids before and during the UCA dose response study (see text) and in patients on longterm UCA therapy

\begin{tabular}{|c|c|c|c|c|c|c|c|c|}
\hline & & \multirow{2}{*}{$\begin{array}{l}\text { Pretreatment } \\
\text { baseline } \\
(10 \mathrm{mg} / \mathrm{kg} / \text { day })\end{array}$} & \multicolumn{3}{|c|}{ Dose-response studies } & \multicolumn{3}{|c|}{ 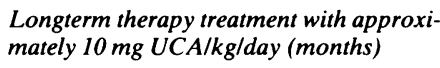 } \\
\hline & & & $5 \mathrm{mg} / \mathrm{kg} /$ day & $10 \mathrm{mg} / \mathrm{kg} /$ day & $15 \mathrm{mg} / \mathrm{kg} /$ day & 6 & 12 & 18 \\
\hline \multicolumn{9}{|c|}{$\begin{array}{l}\text { Liver function tests } \\
\text { ALT }\end{array}$} \\
\hline$(\mathrm{n}<43$ IU/l) & Number & 11 & 7 & 7 & 10 & 8 & 6 & 4 \\
\hline & Mean & $31 \cdot 9$ & $32 \cdot 9$ & $36 \cdot 4$ & $32 \cdot 6$ & $27 \cdot 7$ & $26 \cdot 9$ & $33 \cdot 2$ \\
\hline & SE & $3 \cdot 2$ & $3 \cdot 7$ & $4 \cdot 6$ & $2 \cdot 8$ & $2 \cdot 7$ & $2 \cdot 3$ & $4 \cdot 4$ \\
\hline \multicolumn{9}{|c|}{ ALP } \\
\hline & Mean & $54 \cdot 8$ & 54.9 & $53 \cdot 4$ & 55.9 & $55 \cdot 2$ & $55 \cdot 7$ & $56 \cdot 5$ \\
\hline & SE & $4 \cdot 6$ & $6 \cdot 6$ & $5 \cdot 3$ & $4 \cdot 3$ & $4 \cdot 8$ & $5 \cdot 5$ & 10.9 \\
\hline \multicolumn{9}{|c|}{ Bilirubin } \\
\hline$(\mathrm{n}<17 \mu \mathrm{mol} / \mathrm{l})$ & Number & 11 & 7 & 7 & 10 & 9 & 6 & 4 \\
\hline & Mean & $10 \cdot 5$ & 13.9 & $12 \cdot 4$ & $11 \cdot 1$ & $7 \cdot 9$ & $6 \cdot 0$ & 6 \\
\hline & SE & $1 \cdot 8$ & $2 \cdot 7$ & $2 \cdot 1$ & $3 \cdot 0$ & 1.4 & $1 \cdot 1$ & $1 \cdot 8$ \\
\hline \multicolumn{9}{|c|}{ GGT } \\
\hline$(\mathrm{n}<51 \mathrm{U} / \mathrm{M})$ & Number & 11 & 6 & 7 & 9 & 8 & 4 & 3 \\
\hline$(\mathrm{n}<35 \mathrm{U} / \mathrm{l} \mathrm{F})$ & Mean & $29 \cdot 5$ & $41 \cdot 1$ & $41 \cdot 9$ & $36 \cdot 4$ & $34 \cdot 4$ & $31 \cdot 5$ & $38 \cdot 0$ \\
\hline & SE & $8 \cdot 5$ & $9 \cdot 9$ & $12 \cdot 2$ & $10 \cdot 0$ & $12 \cdot 0$ & $16 \cdot 5$ & $21 \cdot 9$ \\
\hline \multicolumn{9}{|c|}{ Fasting serum lipids } \\
\hline Cholesterol & & & & & & & & \\
\hline$(\mathrm{N}<30 \mathrm{yr}=3 \cdot 1$ & Number & 11 & 6 & 7 & 9 & 8 & 5 & 4 \\
\hline$-6 \cdot 2 ; n>50$ & Mean & $6 \cdot 3$ & $6 \cdot 5$ & $6 \cdot 6$ & $7 \cdot 6$ & $7 \cdot 3$ & $7 \cdot 2$ & $7 \cdot 8$ \\
\hline $\begin{array}{l}\mathrm{yr}=4 \cdot 1-8 \cdot 5 \\
\mathrm{mmol} / \mathrm{l})\end{array}$ & SE & 0.4 & $0 \cdot 5$ & $0 \cdot 6$ & $0 \cdot 4$ & $0 \cdot 6$ & $0 \cdot 6$ & $0 \cdot 7$ \\
\hline \multicolumn{9}{|c|}{ Triglyceride } \\
\hline$(\mathrm{n}<2 \cdot 2 \mathrm{mmol} / \mathrm{l})$ & $\begin{array}{l}\text { Number } \\
\text { Mean }\end{array}$ & $\begin{array}{c}11 \\
2 \cdot 0\end{array}$ & 6 & 7 & $\begin{array}{l}9 \\
2.5\end{array}$ & $\begin{array}{l}8 \\
2 \cdot 2\end{array}$ & 5 & 4 \\
\hline & Mean & & & & $2 \cdot 5$ & & $2 \cdot 6$ & $2 \cdot 1$ \\
\hline
\end{tabular}

diarrhoea, which was experienced by, and necessitated treatment withdrawal in three patients.

\section{HAEMATOLOGY AND CLINICAL CHEMISTRY}

With one exception, there were no haematological abnormalities in any patient before or during UCA treatment. The exception was in patient 2 , who had a raised MCV of 103fl (N86-96) and a high serum gamma glutamyl transpeptidase (GGT) before and during treatment. These abnormalities were attributed to excessive alcohol intake.

The clinical chemistry results (liver function tests and fasting serum lipids), are summarised in Table 3.

\section{Liver function tests}

Although there was a tendency to hypertransaminasaemia during the dose response study, the mean serum alanine transaminase levels remained within the normal range (0-43 U/1) and, in fact, fell after 6,12 , and 18 months treatment with UCA.

Mean serum bilirubin concentrations increased slightly during the dose response studies but again, remained within the normal range. Serum alkaline phosphatase values remained normal in all patients. There were slight, non-sustained increases in serum gamma glutamyl transpeptidase in patients 4 and 5 , which fell to within normal limits during continued treatment.

\section{Fasting serum lipids}

Mean serum cholesterol concentrations were higher at every six week period during the dose response study, compared with baseline, although these differences were not statistically significant. Two of the nine patients treated for six months or more, had raised concentrations of fasting serum cholesterol patient 6 after six months therapy $(8.3 \mathrm{mmol} / \mathrm{l})$ and patient 2 at 18 months $(9.3 \mathrm{mmol} / \mathrm{l})$. Both these patients had increased beta and prebeta lipoproteins.

The mean concentrations of fasting serum triglycerides increased in the patients given $15 \mathrm{mg} / \mathrm{kg}$ / day during the dose response study when there was a $25 \%$ increase above the pretreatment baseline value (NS). Again, patients 2 and 6 had raised serum triglycerides during continued treatment. 


\section{Discussion}

The results of this study fall into two parts: the bile acid and bile lipid dose response studies and the subsequent clinical studies of gall stone dissolution.

\section{DOSE RESPONSE STUDIES}

The decision to treat the patients for six weeks with each UCA dose was based on the results of our previous speed-of-change study with CDCA in which we showed that it took up to four weeks before the bile lipid changes reached a new steady state. ${ }^{17}$ The progressive increase in dose was designed to reduce any carryover effect and to restrict the number of duodenal intubations to a maximum of four.

The dose response study suggested an optimal dose of $10 \mathrm{mg} \mathrm{UCA} / \mathrm{kg} /$ day for gall stone dissolution. Why there should be an apparently less favourable bile lipid response with the $15 \mathrm{mg} / \mathrm{kg}$ dose is not known, although a similar 'plateau' effect has been reported for UDCA. ${ }^{24}$

The enrichment of bile with the administered bile acid during UCA therapy is much less (approximately $25 \%$ of the bile acid total) than that seen during treatment with either CDCA $(75-90 \%)$ or UDCA $(40-55 \%)$. This implies poorer bioavailability of the ingested UCA, greater bacterial degradation, hepatic biotransformation of UCA, or a less potent effect of UCA on primary bile acid synthesis, than occurs with CDCA or UDCA.

Considering each of these points in turn, we have no direct information about UCAs bioavailability. Hepatic biotransformation of ingested UCA seems unlikely. The human liver is not known to isomerise bile acids by converting 7 beta hydroxyl groups to the 7 alpha configuration. Had it done so, the proportion of CA in bile might have risen, rather than fallen. Furthermore, the gas liquid chromatographic results showed no accumulation of 7 keto bile acids in bile (intermediates in the conversion of 7 beta to 7 alpha bile acids). For the reasons already discussed in the Results, UCA may have selectively depressed CA synthesis. We are left, therefore, with the possibility that intestinal bacteria 7 beta dehydroxylate the ingested UCA, to form DCA. This is supported by the $41 \%$ increase in DCA conjugates in bile during UCA therapy - particularly since the proportion of CA, which is the usual precursor of DCA, was decreased.

CLINICAL TRIAL OF DISSOLUTION EFFICACY AND SAFETY

In contrast to the results of Zuin and Podda ${ }^{18}$ who reported complete gall stone dissolution in three of six patients with small ( $<5 \mathrm{~mm}$ diameter), floating stones, we found that only one patient achieved complete gall stone dissolution.

The present results have shown no evidence that UCA is hepatotoxic. Indeed, the mean ALT concentrations fell during UCA therapy. The significance of this observation is unknown but an apparent improvement in liver function has been reported during CDCA and UDCA treatment in gall stone patients ${ }^{25}$ and in patients with primary biliary cirrhosis during UDCA therapy. ${ }^{26}$

The fasting serum cholesterol results seen in the present dose response studies, are a cause for concern, in spite of the small number of patients studied.

Unfortunately, UCA therapy produced troublesome diarrhoea in three of the 13 patients. This was probably caused by 'spillover' of cathartic bile acids, particularly DCA, into the colon.

In conclusion, UCA has limited efficacy in dissolving gall stones and as it caused diarrhoea in three of 13 patients and increased mean fasting serum cholesterol concentrations, it confers no advantages over existing forms of bile acid therapy. Nevertheless, the present study makes important contributions to our knowledge about the biochemical and potential therapeutic effects of short term and long term treatment with different bile acids in man, knowledge which can only be gained through clinical experience.

This study was presented in part at a meeting of the Medical Research Society (Howard et al [Abstract]. Clin Sci 1984; 67: 100-1).

These studies were supported, in part, by grants from Gipharmex SpA, Milan (who also kindly supplied the ursocholic acid capsules) and by the Special Trustees of Guy's Hospital. Thanks are due to Cathy Weeks and Ann Hollington for their secretarial help and to Mr Y Qureshi for technical assistance. We also wish to thank Dr R J Prescott, Senior Lecturer in the Medical Statistics Unit, University of Edinburgh, for his helpful advice during the preparation of this paper.

\section{References}

1 Dowling RH. Chenodeoxycholic acid therapy of gallstones. In: Paumgartner G, ed. Clinics in gastroenterology; bile acids. London: WB Saunders Co Ltd, 1977: 141-63.

2 Dowling RH, Hofmann AF, Barbara L, eds. Workshop on ursodeoxycholic acid. Lancaster: MTP Press, 1978: $1-88$.

3 Mok HYI, Bell GD, Dowling RH. Effect of different doses of chenodeoxycholic acid on bile-lipid composition and on frequency of side-effects in patients with gallstones. Lancet 1974; ii: 253-7.

4 Iser JH, Dowling RH, Mok HYI, Bell GD. Chenodeoxycholic acid treatment of gallstones $-\mathbf{a}$ follow-up report 
and analysis of factors influencing response to therapy. N Engl J Med 1975; 293: 378-83.

5 Thistle JL, Hofmann AF. Efficacy and specificity of chenodeoxycholic acid therapy for dissolving gallstones. N Engl J Med 1973; 289: 655-9.

6 Bell GD, Mok HYI, Thwe M, Murphy GM, Henry K. Dowling RH. Liver structure and function in cholelithiasis: effect of chenodeoxycholic acid. Gut 1974; 15: 165-72.

7 Gleeson DC, Ruppin DC, Dowling RH. Second look at ursodeoxycholic acid (UDCA): high efficacy for partial but low efficacy for complete gallstone dissolution and a high rate of acquired stone opacification [Abstract]. Gut 1983; 24: A999.

8 Bateson MC, Bouchier IAD, Trash DB, Maudgal DP, Northfield TC. Calcification of radiolucent gallstones during treatment with ursodeoxycholic acid. $\mathrm{Br}$ Med $J$ 1981; 283: 645-6.

9 Tint GS, Salen G, Colalillo A, et al. Ursodeoxycholic acid: a safe and effective agent for dissolving cholesterol gallstones. Ann Intern Med 1983; 97: 351-6.

10 Czygan P. Efficacy of combined ursodeoxycholic and chenodeoxycholic acid treatment. In: Paumgartner G, Stiehl A, Gerok W, eds. Bile acids and the liver. Lancaster: MTP Press, 1987: 343-4.

11 Roehrakasse R, Fromm H, Malavolti M, Anand K, Tunuguntla AK, Ceryak S. Gallstone dissolution treatment with a combination of Chenodeoxycholic and Ursodeoxycholic acids. Studies of safety, efficacy and effects of bile lithogenicity, bile acid pool and serum lipids. Dig Dis Sci 1986; 31: 1032-40.

12 Podda M, Zuin M, de Fazio C, Dioguardi ML, Battezzati PM, Ghezzi C. Comparison of the efficacy and safety of ursodeoxycholic alone and in combination with chenodeoxycholic acid in patients with radiolucent gallstones: a randomized controlled trial. In: Paumgartner G, Stiehl A, Gerok W, eds. Bile acids and the liver. Lancaster: MTP Press, 1987: 347-52.

13 Thistle JL. Dissolution of gallstones using ursodeoxycholic acid with or without chenodeoxycholic acid or taurine. In: Paumgartner G, Stiehl A, Gerok W, eds. Bile acids and the liver. Lancaster: MTP Press, 1987: $353-4$.

14 Carulli N, Ponz de Leon M, Loria P, Iori R, Rosi A, Romani M. Effect of the selective expansion of the cholic acid pool on bile lipid composition: possible mechanism of bile acid induced biliary cholesterol desaturation. Gastroenterology 1981; 81: 539-46.
15 Yahiro K, Setoguchi T, Katsuki T. Effect of caecum and appendix on 7 alpha dehydroxylation and 7 beta epimeriation of chenodeoxycholic acid in the rabbit. J Lipid Res 1980; 21: 215-22.

16 Loria P, Carulli N, Medici G, et al. Effect of ursocholic acid on bile lipid secretion and composition. Gastroenterology 1986; 90: 865-74.

17 Iser JH, Murphy GM, Dowling RH. Speed of change in biliary lipids and bile acids with chenodeoxycholic acid is intermittent therapy feasible? Gut 1977; 18: 7-15.

18 Zuin M. Podda M. Ursocholic acid; a new litholitic agent [Abstract]. Hepatology 1984; 4: 1060.

19 Maton PN, Iser JH, Reuben A, Saxton HM, Murphy GM, Dowling RH. Outcome of chenodeoxycholic acid (CDCA) treatment of 125 patients with radiolucent gallstones. Factors influencing efficacy, withdrawal, symptoms and side-effects and post-dissolution recurrence. Medicine (Baltimore) 1982; 61: 86-97.

20 Thomas PH, Hofmann AF. A simple calculation of the lithogenic index of bile: Expressing biliary lipid composition on rectangular coordinates. Gastroenterology 1973; 65: 698-700.

21 Hegardt FG, Dam $H$. The solubility of cholesterol in aqueous solutions of bile salts and lecithin. $Z$ Ernahrungswiss 1971; 10: 223-33.

22 Holzbach RT, Narsh M, Olszewski M, Holan K. Cholesterol solubility in bile: evidence that supersaturated bile is frequent in healthy man. J Clin Invest 1973; 52: 1467-79.

23 Carey MC, Ko G. The importance of total lipid concentration in determining cholesterol solubility in bile and the development of critical tables for calculating $\%$ cholesterol saturation' with a correction factor for ursodeoxycholic-rich bile. In: Paumgartner G, Stiehl A, Gerok W, eds. Biological Effects of Bile Acids. Lancaster: MTP Press, 1979: 298-308.

24 Erlinger S, Le Go A, Husson J-M, Fevery J. FrancoBelgian Cooperative Study of ursodeoxycholic acid in the medical dissolution of gallstones: a double-blind, randomized, dose-response study, and comparison with chenodeoxycholic acid. Hepatology 1984; 4: 308-14.

25 Bateson MC, Ross PE, Murison J, Saunders JHB, Bouchier IAD. Ursodeoxycholic acid therapy and biliary lipids - a dose-response study. Gut 1980; 21: 30510.

26 Poupon R, Chretien Y, Poupon RE, Ballet F, Calmus Y, Darnis F. Is Ursodeoxycholic acid an effective treatment for primary biliary cirrhosis? Lancet 1987 ; i: $834-6$. 